\title{
Pharmacological inhibition of leukotrienes in an animal model of bleomycin-induced acute lung injury
} Marco Failla ${ }^{\dagger 1}$, Tiziana Genovese ${ }^{\dagger 2,3}$, Emanuela Mazzon ${ }^{2,3}$, Elisa Gili ${ }^{1}$, Carmelo Muià 2,3 , Mariangela Sortino ${ }^{4}$, Nunzio Crimi ${ }^{1}$, Achille P Caputi ${ }^{2,3}$, Salvatore Cuzzocrea ${ }^{\dagger 2,3}$ and Carlo Vancheri*1

Address: ${ }^{1}$ Department of Internal Medicine and Specialistic Medicine, Section of Respiratory Diseases, University of Catania, Catania, Italy, ${ }^{2}$ Department of Clinical and Experimental Medicine and Pharmacology, University of Messina, Messina, Italy, ${ }^{3}$ Centro per lo Studio e il Trattamento dei Neurolesi Lungodegenti, University of Messina, Messina, Italy and ${ }^{4}$ Department of Clinical and Experimental Medicine and Pharmacology, Catania, Italy

Email: Marco Failla - marcofailla@yahoo.it; Tiziana Genovese - genovese@unime.it; Emanuela Mazzon - mazzon@unime.it; Elisa Gili - elisagili@hotmail.com; Carmelo Muià - muia@unime.it; Mariangela Sortino - Sortino@unict.it; Nunzio Crimi - crimi@unict.it; Achille P Caputi - caputi@unime.it; Salvatore Cuzzocrea - salvator@unime.it; Carlo Vancheri* - vancheri@unict.it

* Corresponding author †Equal contributors

Published: 2I November 2006

Respiratory Research 2006, 7:137 doi:10.1 186/1465-992I-7-137
Received: 12 July 2006

Accepted: 21 November 2006

This article is available from: http://respiratory-research.com/content/7/I//37

(c) 2006 Failla et al; licensee BioMed Central Ltd.

This is an Open Access article distributed under the terms of the Creative Commons Attribution License (http://creativecommons.org/licenses/by/2.0), which permits unrestricted use, distribution, and reproduction in any medium, provided the original work is properly cited.

\begin{abstract}
Leukotrienes are increased locally in idiopathic pulmonary fibrosis. Furthermore, a role for these arachidonic acid metabolites has been thoroughly characterized in the animal bleomycin model of lung fibrosis by using different gene knock-out settings.

We investigated the efficacy of pharmacological inhibition of leukotrienes activity in the development of bleomycin-induced lung injury by comparing the responses in wild-type mice with mice treated with zileuton, a 5-lipoxygenase inhibitor and MK-57I, a cys-leukotrienes receptor antagonist.

Mice were subjected to intra-tracheal administration of bleomycin or saline and were assigned to receive either MK-57l at I mg/Kg or zileuton at $50 \mathrm{mg} / \mathrm{Kg}$ daily. One week after bleomycin administration, BAL cell counts, lung histology with van Gieson for collagen staining and immunohistochemical analysis for myeloperoxidase, IL-I and TNF- $\alpha$ were performed.

Following bleomycin administration both MK-57I and zileuton treated mice exhibited a reduced degree of lung damage and inflammation when compared to WT mice as shown by the reduction of:(i) loss of body weight, (ii) mortality rate, (iii) lung infiltration by neutrophils (myeloperoxidase activity, BAL total and differential cell counts), (iv) lung edema, (v) histological evidence of lung injury and collagen deposition, (vi) lung myeloperoxidase, IL-I and TNF- $\alpha$ staining.

This is the first study showing that the pharmacological inhibition of leukotrienes activity attenuates bleomycin-induced lung injury in mice. Given our results as well as those coming from genetic studies, it might be considered meaningful to trial this drug class in the treatment of pulmonary fibrosis, a disease that still represents a major challenge to medical treatment.
\end{abstract}




\section{Background}

Idiopathic pulmonary fibrosis (IPF) is the most common interstitial pneumonias of unknown origin and one of the most aggressive interstitial lung diseases. It is characterized by a chronic and progressive course leading to respiratory failure with a median survival under 3 years [1-3]. The pathogenesis of this condition is not entirely understood, but the activation and proliferation of fibroblasts in response to multiple and microscopic episodes of alveolar epithelial injury is believed to be the main event which ultimately leads to extracellular matrix components remodelling, resulting in the irreversible distortion of the lung architecture [4].

A number of studies suggest a causal role for leukotrienes (LT) in lung fibrosis [5]. These are lipid mediators derived by the hydrolysis from membrane phospholipids of arachidonic acid by the phospholipase A2 and 5-lipoxygenase[6]. Leukotriene $\mathrm{B}_{4}$ is elevated in the bronchoalveolar lavage of patients with IPF $[7,8]$. Furthermore cys-LT and LT- $\mathrm{B}_{4}$ are increased in lung homogenates of patients with $\mathrm{IPF}$, and the levels of these mediators were found to correlate with the extent of fibrosis in histological sections [9]. Increased LT levels have also been demonstrated in mice lungs following intra-tracheal administration of bleomy$\operatorname{cin}[10]$.

The leukotrienes pathway has been recently dissected in the bleomycin animal model of lung fibrosis using different genetic backgrounds. Knocking out each of the enzymes involved in the cascade from membrane phospholipids to leukotrienes, such as phospholipase- $\mathrm{A}_{2}$, 5lipoxygenase (LO), as well as $\mathrm{LTC}_{4}$ synthase, invariably attenuates fibrosis in mice [11-13]. However, results coming from these genetically altered backgrounds have not been confirmed using a pharmacological approach, so that no data exist actually on the efficacy of selective drugs targeted on the leukotrienes pathway approved today for human use.

This lack of data prompted us to ascertain whether the cysteinyl leukotrienes receptor-1 antagonist MK-571 and the 5-LO specific inhibitor Zileuton were able to affect the inflammatory and fibrosing process that characterize the intratracheal instillation of bleomycin in mice.

\section{Methods \\ Animals}

Male CD mice (25-35 g; Harlan Nossan; Italy) were housed in a controlled environment and provided with standard rodent chow and water. Animal care was in compliance with Italian regulations on protection of animals used for experimental and other scientific purpose (D.M. 116192 ) as well as with the EEC regulations (O.J. of E.C. L 358/1 12/18/1986).

\section{Experimental groups}

Mice were randomly allocated into the following groups:

(i) WT+BLEO group. Mice were subjected to bleomycininduced lung injury ( $\mathrm{N}=15)$, (ii) WT+saline group. Sham-operated group in which saline was administered instead of bleomycin, $(N=15)$. (iii) MK-571 group. Same as the $\mathrm{WT}+\mathrm{BLEO}$ group but mice were administered with MK-571 delivered through a subcutaneous implanted Alzet 2002 mini-osmotic pump (Durect Co., Cupertino, CA, USA). This route of administration was preferred over oral administration on the basis of unknown pharmacokinetic properties of MK571 because of constant drug delivery. The pump loaded with $200 \mu \mathrm{L}$ of a $2.5 \mu \mathrm{g} / \mu \mathrm{L}$ MK-571 solution in PBS (Cayman Chemical, Ann Arbor, MI, USA) had a release rate of $0.5 \mu \mathrm{L} /$ hour during the 7 days of the experimental setup, $(\mathrm{N}=15)$. (iv) Sham $+\mathrm{MK}-571$ group. Identical to WT+saline group, except for the administration of MK-571 delivered as described above $(\mathrm{N}=15)$. (v) Zileuton group. Same as the WT+BLEO group but WT mice were administered Zileuton by force-feeding (Sequoia Research Products, Oxford, U.K.) with a $50 \mathrm{mg} /$ $\mathrm{kg}$ oral bolus 30 minutes after bleomycin instillation and then daily in the subsequent days $(\mathrm{N}=15)$. The concentration of MK-571 was established on the basis of preliminary experiments starting from what was available on other animal models [14], while zileuton dose and route administration was chosen according to our precedent studies [15]. (vi) Sham+Zileuton. Identical to WT+saline group, except for the administration of zileuton as previously described $(\mathrm{N}=15)$.

\section{Induction of lung injury by bleomycin}

Mice received a single intratracheal instillation of saline $(0.9 \%)$ or saline containing bleomycin sulphate $(1 \mathrm{mg} / \mathrm{kg}$ body weight) in a volume of $50 \mu \mathrm{l}$ and were killed after 7 days by pentobarbitone overdose.

\section{Measurement of fluid content in lung}

The wet lung weight was measured after careful excision of extraneous tissues. The lung was exposed for $48 \mathrm{~h}$ at $180^{\circ} \mathrm{C}$ and the dry weight was measured. Water content was calculated by subtracting dry weight from wet weight.

\section{Histological examination}

Excised lung were taken 7 days after injection of bleomycin, processed as previously described[16], and stained by the van Gieson stain for collagen. The severity of fibrosis was semi-quantitatively assessed according to Ashcroft and co-workers[17]. Briefly, the grade of lung fibrosis was scored on a scale from 0 to 8 by examining randomly chosen fields of the left middle lobe at a magnification of $\times 100$. Criteria for grading lung fibrosis were as follows: grade 0 , normal lung; grade 1, minimal fibrous thickening of alveolar or bronchiolar walls; grade 3, moderate thick- 
ening of walls without obvious damage to lung architecture; grade 5, increased fibrosis with definite damage to lung structure and formation of fibrous bands or small fibrous masses; grade 7 , severe distortion of structure and large fibrous areas; grade 8 , total fibrous obliteration of fields. Grades 2, 4 and 6 were used as intermediate pictures between the aforementioned criteria. All sections were scored by a single investigator in a blinded fashion.

\section{Immunohistochemical localization of IL-I $\beta$ and TNF- $\alpha$} IL- $1 \beta$ and TNF- $\alpha$ were determined by immunohistochemistry as previously described [16]. Sections were incubated overnight with anti-IL-1 $\beta$ or anti-TNF- $\alpha$ (Santa Cruz Biotechnology Inc., Santa Cruz, CA, USA) polyclonal antibody (both at 1:500 in PBS, v/v). Specific labelling was detected with a biotin-conjugated goat anti-rabbit IgG and avidin-biotin peroxidase complex (DBA, Milan, Italy). Controls included buffer alone or non-specific, purified rabbit IgG. Immunocytochemistry photographs were assessed by densitometry. By using Optilab Graftek software on a Macintosh personal computer, the assay was performed.

\section{Myeloperoxidase activity assay}

Myeloperoxidase (MPO) activity, an indicator of polymorphonuclear leukocyte (PMN) accumulation, was determined as previously described in lung homogenates. The rate of change in absorbance was measured spectrophotometrically at $650 \mathrm{~nm}$. MPO activity was defined as the quantity of enzyme degrading $1 \mu \mathrm{Mol}$ of peroxide/ $\min$ at $37^{\circ} \mathrm{C}$ and was expressed in milli-units per $\mathrm{g}$ of wet tissue.

\section{Bronchoalveolar Lavage (BAL)}

Seven days after bleomycin or saline solution instillation, mice were euthanized and the trachea was cannulated. Lungs were lavaged once with $0.5 \mathrm{ml}$ D-PBS (GIBCO, Paisley, U.K.). In $>95 \%$ of the mice, the recovery volume was over $0.4 \mathrm{ml}$. Total BAL cells were enumerated by counting on a haemocytometer in the presence of trypan blue. Cytospins were prepared from resuspended BAL cells. A total of 400 cells were counted from randomly chosen high power microscope fields for each sample.

\section{Materials}

Unless otherwise stated, all compounds were obtained from Sigma-Aldrich Company Ltd. (Poole, Dorset, U.K.). All other chemicals were of the highest commercial grade available. All stock solutions were prepared in non-pyrogenic saline ( $0.9 \% \mathrm{NaCl}$; Baxter, Italy, UK).

\section{Statistical evaluation}

All values in the figures and text are expressed as mean \pm standard error of the mean (SEM) of $\mathrm{N}$ observations. For the in vivo studies $\mathrm{N}$ represents the total number of ani- mals studied, dead animals were replaced in further experiments to reach the specified number of observations. In the experiments involving histology or immunohistochemistry, the figures shown are representative of at least three experiments performed on different experimental days. The results were analyzed by one-way ANOVA followed by a Bonferroni post-hoc test for multiple comparisons. A P-value of less than 0.05 was considered significant. Statistical analysis for survival data was calculated by Fisher's exact probability test. For such analyses, $\mathrm{p}<0.05$ was considered significant.

\section{Results}

Histological examination of lung sections revealed significant tissue damage. Thus, when compared to lung sections taken from saline-treated animals, histological examination of WT mice treated with bleomycin were characterized by extensive inflammatory infiltration by neutrophils, lymphocyte and plasma cells extending through the lung epithelium, fibrosis and granulomas were seen in perivascular region (Fig. 1a and 1b). The inhibition of the leukotrienes activity in mice (animals treated with either MK 571 or Zileuton) significantly prevented lung inflammation induced by bleomycin administration (Figs. 1c and 1d, respectively).

Lung fibrosis grading [17] revealed a moderate to severe fibrosis reaction after one week of bleomycin administration, which was significantly reduced in animals treated with MK-571 and Zileuton (6.1+/-0.5 vs. $2.1+/-0.3$ and $1.7+/-0.6, p<0.01$, Fig. 1e). Sham treated animals were found to be constantly free from lung inflammation and fibrosis.

Bleomycin elicited an inflammatory response characterized by the accumulation of water in lung as an indicator of lung edema, (Fig. 1f) and neutrophils infiltration in the lung tissues in WT-animals. The leukotrienes synthesis inhibition and the receptor blockade in bleomycin treated mice significantly reduced the fluid content (Fig. 1f) and the neutrophil infiltration (Figs. 2d) as evaluated by MPO activity assay. Neutrophil activity was also evaluated immunohistochemically by MPO staining of lung sections, demonstrating a strong alveolar neutrophils infiltration (Fig. 2a). This effect was completely abrogated in MK-571 and Zileuton treated animals (Figs. 2b,c).

Immunohistochemical analysis revealed a positive staining for IL-1 $\beta$ mostly in inflammatory cell infiltrate present in the interstitium and in the airspace (i.e. alveolar macrophages) but also in the vascular zone (i.e. vascular endothelium) in bleomycin-group (Fig. 3a). In contrast, no staining for IL-1 $\beta$ was found in the lungs of MK-571 (Fig. 3b) and Zileuton groups (Fig. 3c). 

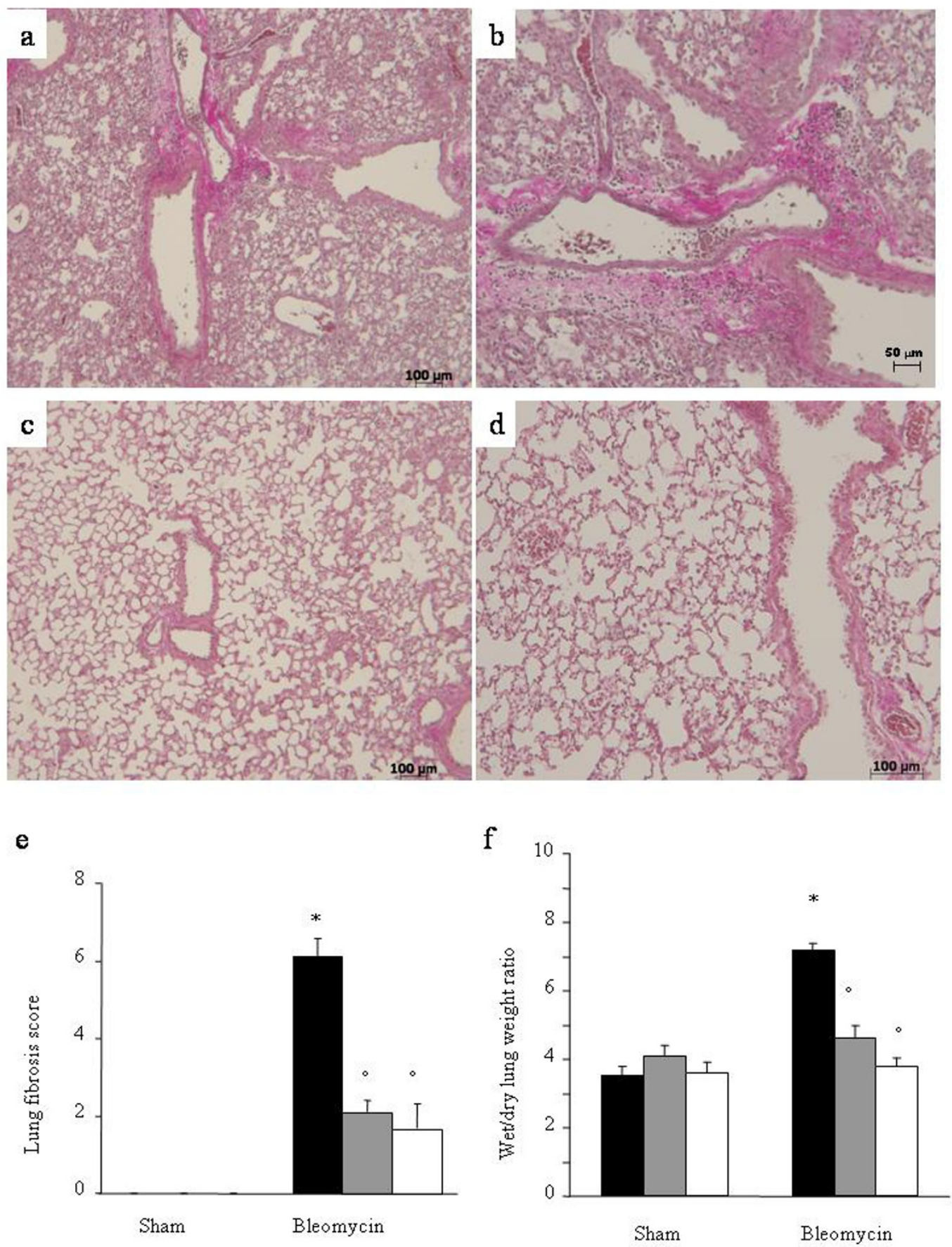

\section{Figure I}

Effect of leukotrienes pathway pharmacological inhibitionon lung injury. Van Gieson stain: $\times 150$. The used stain shows collagen in purple. A: Bleomycin alone in WT mice. B: Magnified lung section of Bleomycin alone in WT mice, $\times 300$. C: Bleomycin in MK-57I treated mice. D: Bleomycin in Zileuton treated mice. All showed sections come from the left middle lobe. Each image is representative of at least 3 experiments. E: Lung fibrosis as evaluated by Ashcroft criteria[I7]. F: Effect of pharmacological leukotrienes activity inhibition on edema in the lung. Black bar represents control group, grey bar MK-57I group and white bar Zileuton group. Data are means \pm SEM from I 5 mice for each group. ${ }^{*} \mathrm{P}<0.01$ versus sham. ${ }^{\circ} \mathrm{P}<0.01$ vs. bleomycin. 

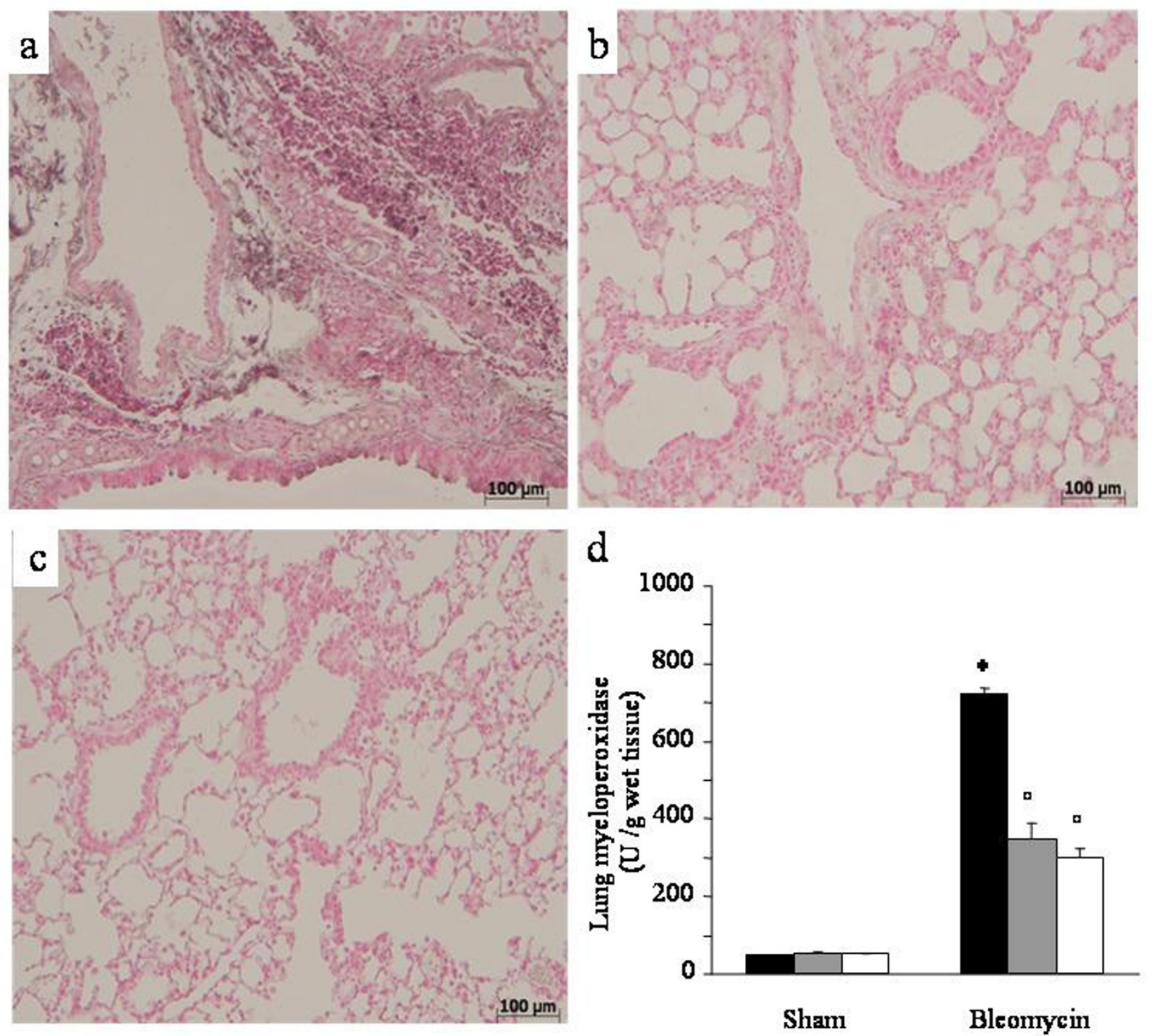

\section{Figure 2}

Effect of pharmacological leukotrienes activity inhibition on lung myeloperoxidase. Immunohistochemical localization of myeloperoxidase in the lung. A: Bleomycin alone in WT mice. B: Bleomycin in MK-57I treated mice. C: Bleomycin in Zileuton treated mice. Original magnification: I50×. Each image is representative of at least 3 experiments. D: Effect of pharmacological leukotrienes activity inhibition on lung myeloperoxidase activity. Black bar represents control group, grey bar MK-57I group and white bar Zileuton group. Data are means \pm SEM from I 5 mice for each group. ${ }^{*} \mathrm{p}<0.0 \mathrm{I}$ versus sham. ${ }^{\circ} \mathrm{P}<0.0 \mathrm{I}$ vs. bleomycin.

Similarly, a substantial increase in the lung TNF- $\alpha$ staining of bronchial epithelial cells was evident in bleomycin group (Fig. 3e). This effect was reduced in lung sections of MK-571 (Fig. 3f) and Zileuton treated animals (Fig. 3g) caused by bleomycin intratracheal administration. There was no IL- $1 \beta$ or TNF- $\alpha$ staining in lung sections of shamoperated animals.

The severe lung injury caused by bleomycin administration was associated with a significant loss in body weight 

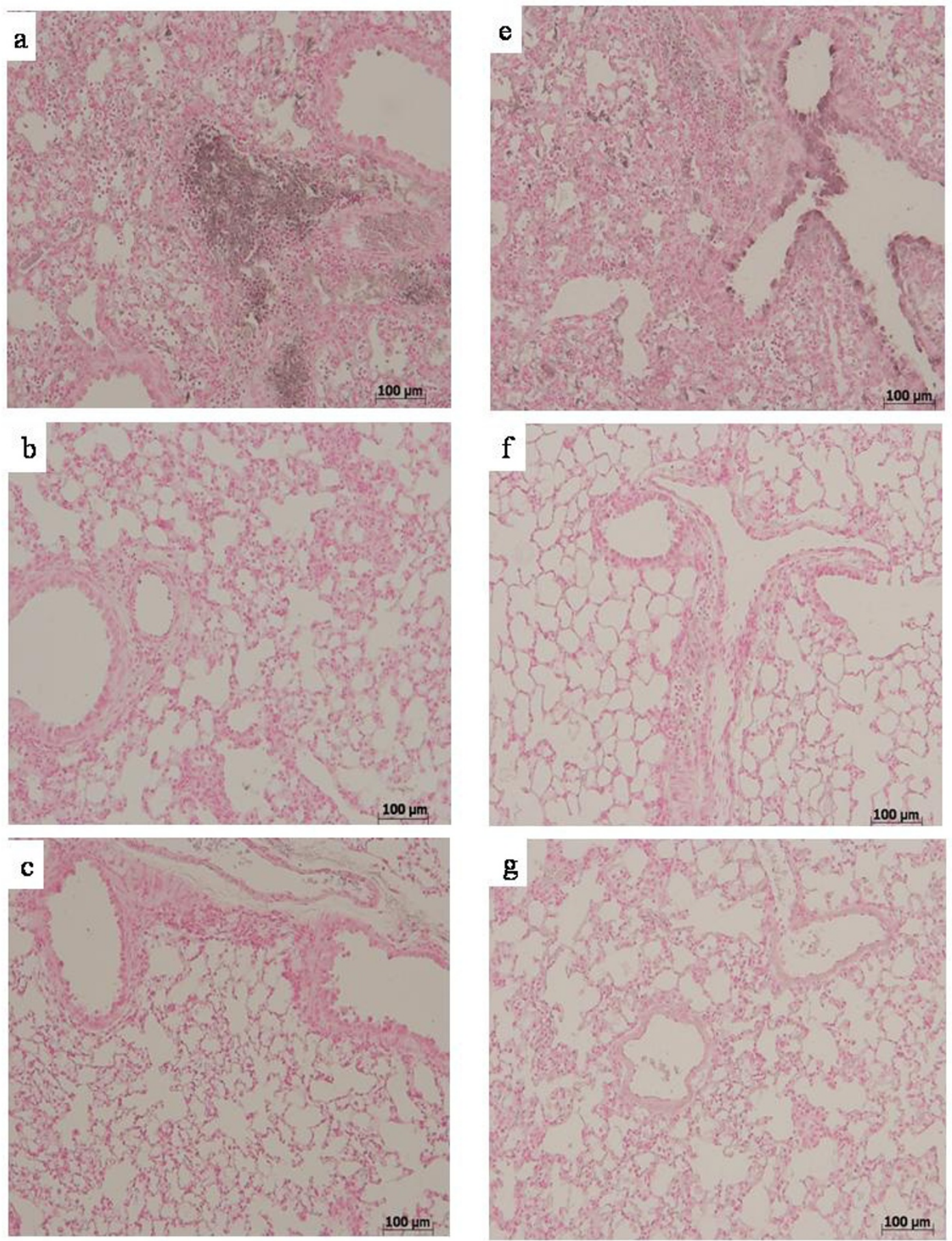

\section{Figure 3}

Effect of pharmacological leukotrienes activity inhibition on lung IL-I and TNF- $\alpha$ immunostaining. After bleomycin injection in WT mice, positive staining for IL-I (A) was localized mainly in inflammatory cells and in vascular endothelium. There was a marked reduction in the IL-I immunostaining in the lungs of MK-57I group (B) and in the lungs of Zileuton group (C). TNF- $\alpha$ was localized mainly in inflammatory cells and in bronchial epithelium of lungs in the bleomycin group (E). A marked reduction in TNF- $\alpha$ immunostaining in lungs of MK-57I (F) and in Zileuton group (G). Original magnification: I50x. This figure is representative of at least 3 experiments performed on different experimental days. 
and survival (Figs. 4a,b). Leukotrienes synthesis blockade and the receptor antagonism in bleomycin treated mice significantly attenuated the loss in body weight. Bleomycin-treated WT mice developed severe lung injury and $33 \%$ of these animals died within one week after bleomycin administration. None of the MK-571 or Zileuton treated animals died after bleomycin instillation within the one week period of study.

BAL total cellularity significantly increased in bleomycin exposed animals (Fig. 5a). MK-571 and Zileuton groups showed a reduction in BAL cellularity when compared to bleomycin group.

Differential cell counts showed a similar profile across all of the sham groups. In the bleomycin group there was a significant increase of macrophages, lymphocytes and neutrophils compared to sham group.

MK-571 and Zileuton treated mice showed a decreased content of BAL inflammatory cells as evaluated on cytospins preparations (Fig. 5b). In these mice macrophages, lymphocytes and neutrophils were significantly reduced compared to bleomycin group.

\section{Discussion}

Common pathologic features in interstitial lung diseases include the fibrosis of the interstitium, involve collagen, elastic and smooth muscle elements, architectural remodelling and chronic inflammation[18].

Lipid mediators are thought to be involved in lung fibrosis. Cysteinyl leukotrienes as well as LT-B4 are elevated in lung homogenates and bronchoalveolar lavage of patients with IPF [19-21]. In lung fibroblasts, leukotrienes stimulate collagen synthesis, chemotaxis, and transformation into myofibroblasts [22-24].

Observations on the role of leukotrienes in vivo come from the experimental model of bleomycin-induced lung fibrosis. Intratracheal instillation of the antitumour agent bleomycin is the most commonly used animal model for pulmonary fibrosis[25]. Earlier reports point out that the pathogenesis of bleomycin-induced fibrosis, at least in part, is mediated through the generation of reactive oxygen species which cause the peroxidation of membrane lipids and DNA damage[26].

Early attempts to target the arachidonic acid metabolism in this experimental model were performed using a pharmacological approach. Lpoxygenase inhibitor nordihydroguaiaretic acid was proved to attenuate bleomycininduced lung fibrosis and to reduce both the macrophage infiltrate and the fibroblast growth factor release after bleomycin administration[27]. However, this compound is characterized by a non-specific action on arachidonic acid metabolism and has proved to possess a direct anti-oxidant activity [28]. Similarly, gamma-linolenic acid was able to suppress LT- $\mathrm{B}_{4}$ synthesis and lung damage in this model[29], but again its action is not limited to the arachidonic acid pathway[30].

Recently, leukotrienes pathway in this model has been dissected by genetically targeting the different enzymes responsible for the synthesis of eicosanoids. Indeed, lung fibrosis and inflammation were attenuated by the disruption of the gene encoding phospholipase $\mathrm{A}_{2}$ in this model[31]. Peters-Golden et al[32], demonstrated how 5LO deficient mice were protected by bleomycin-induced lung fibrosis, thus confirming LT role in experimental pulmonary fibrosis. More recently, Beller and colleagues have demonstrated a role for LT- $\mathrm{C}_{4}$ synthase and for the cysteinyl leukotriene receptors in the pathogenesis of the fibrotic lung damage following bleomycin. Whereas the cys- $\mathrm{LT}_{1}$ receptor is involved in the acute damage, cys-LT2 receptor is thought to be responsible for the chronic injury following bleomycin administration[33,34].

However, it has to be underscored that murine alveolar macrophages present higher levels of cys-LTs than LTB4 with an inverted ratio between the two [35]. Thus, murine models are expected to exaggerate the importance of cysLTs relative to what would occur in humans [36].

Considering that overproduction of 5-LO products occurs in the bleomycin animal model of lung fibrosis, and that previous studies on genetic knock out of different enzymes involved in leukotrienes synthesis have shown a significant protection from bleomycin induced fibrosis, we sought to assess the role of drugs that target the leukotriene pathway either at the synthetic step or at the receptor level.

In the current study, we used MK-571 as a specific cys- $\mathrm{LT}_{1}$ receptor antagonist[37]. This compound has similar biochemical and pharmacological properties to other antileukotrienes drugs such as montelukast, currently used to treat bronchial asthma and allergic rhinitis. Whereas Zileuton is a reversible 5-LO inhibitor approved for the treatment of asthma in humans. It is noteworthy that zileuton dose used in our experimental setup was very close to that clinically used in humans (1.5 times). On the other hand, it is not possible to estimate a relative dose for MK571, because of the unavailability of human studies with this particular compound.

Here we show a significant reduction of tissue damage in lungs of bleomycin-treated mice which received the treatment with both MK-571 or Zileuton. Not only did the matrix deposition evaluated histologically in lung sec- 
a.

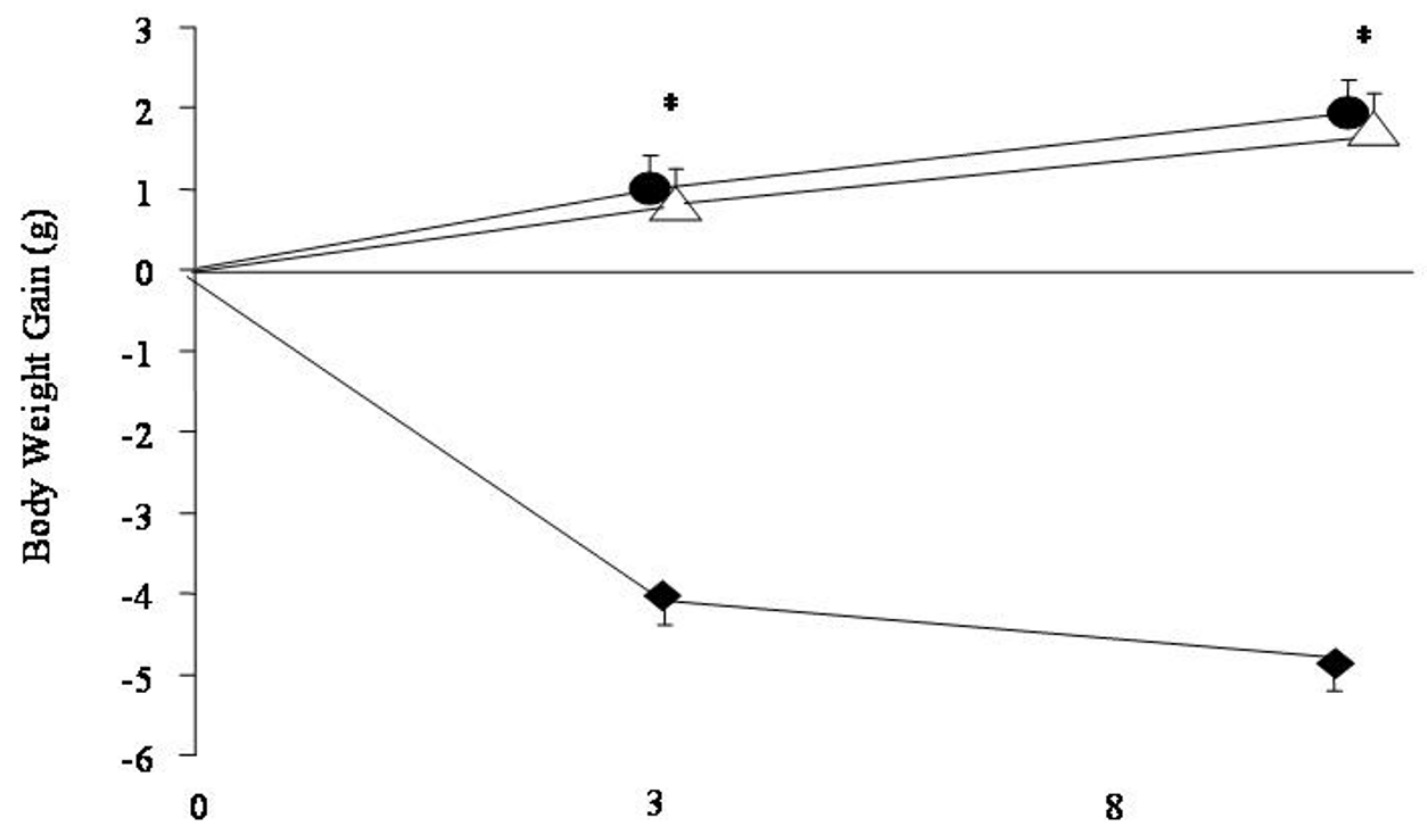

Days

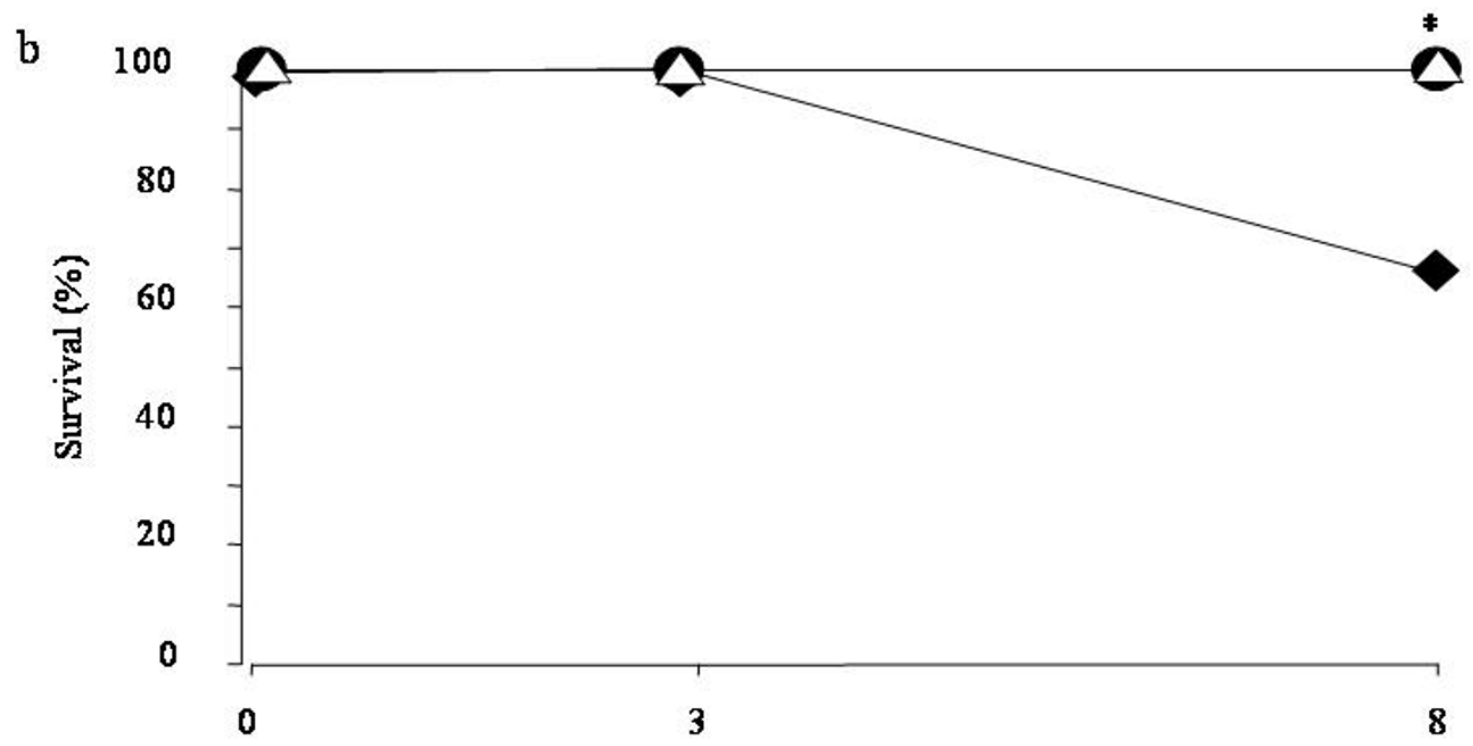

Days

Figure 4

Effect of pharmacological inhibition of leukotrienes activity on body weight (A) and survival (B). $\bullet$ represents bleomycin group, $\mathrm{MK}-57 \mathrm{I}$ treated animals and $\Delta$ Zileuton treated animals. Data are means \pm SEM from I 5 mice for each group. *p $<0.01$ vs. bleomycin. 
a

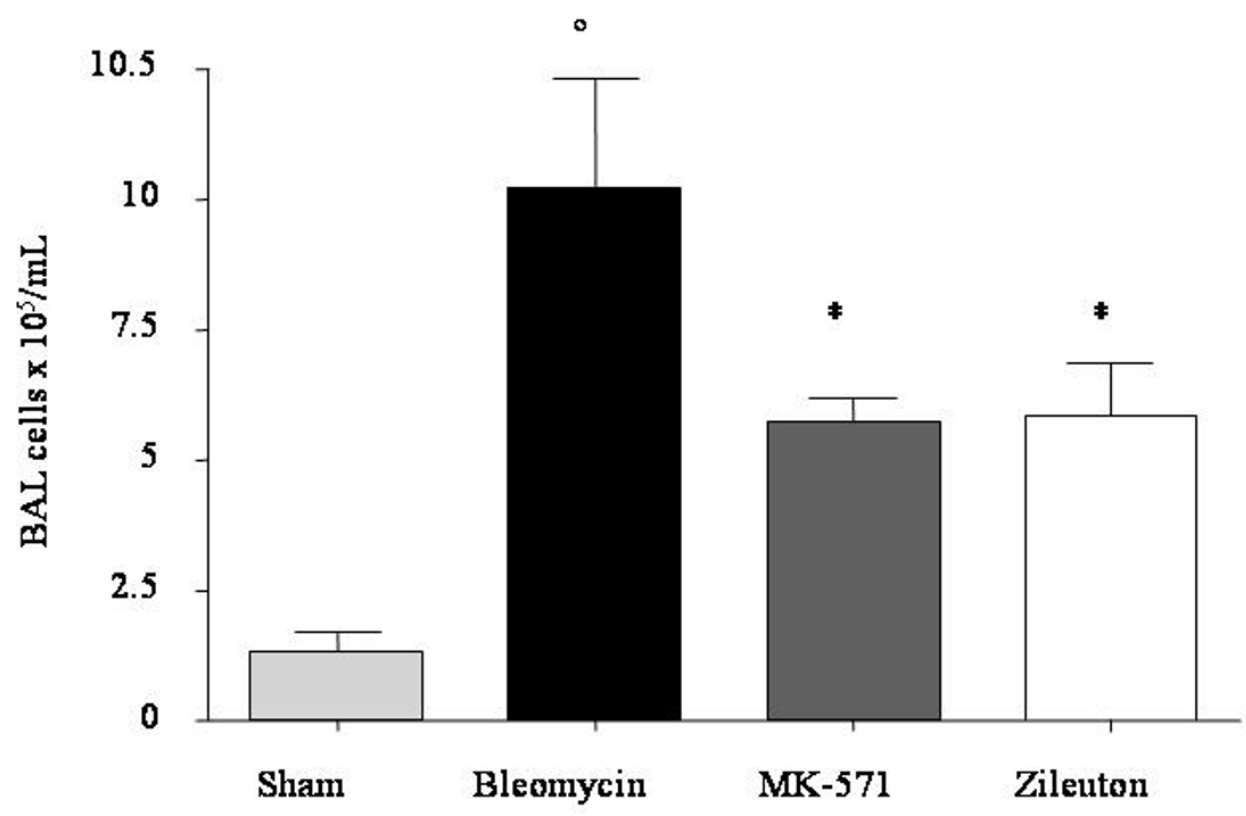

$\mathrm{b}$

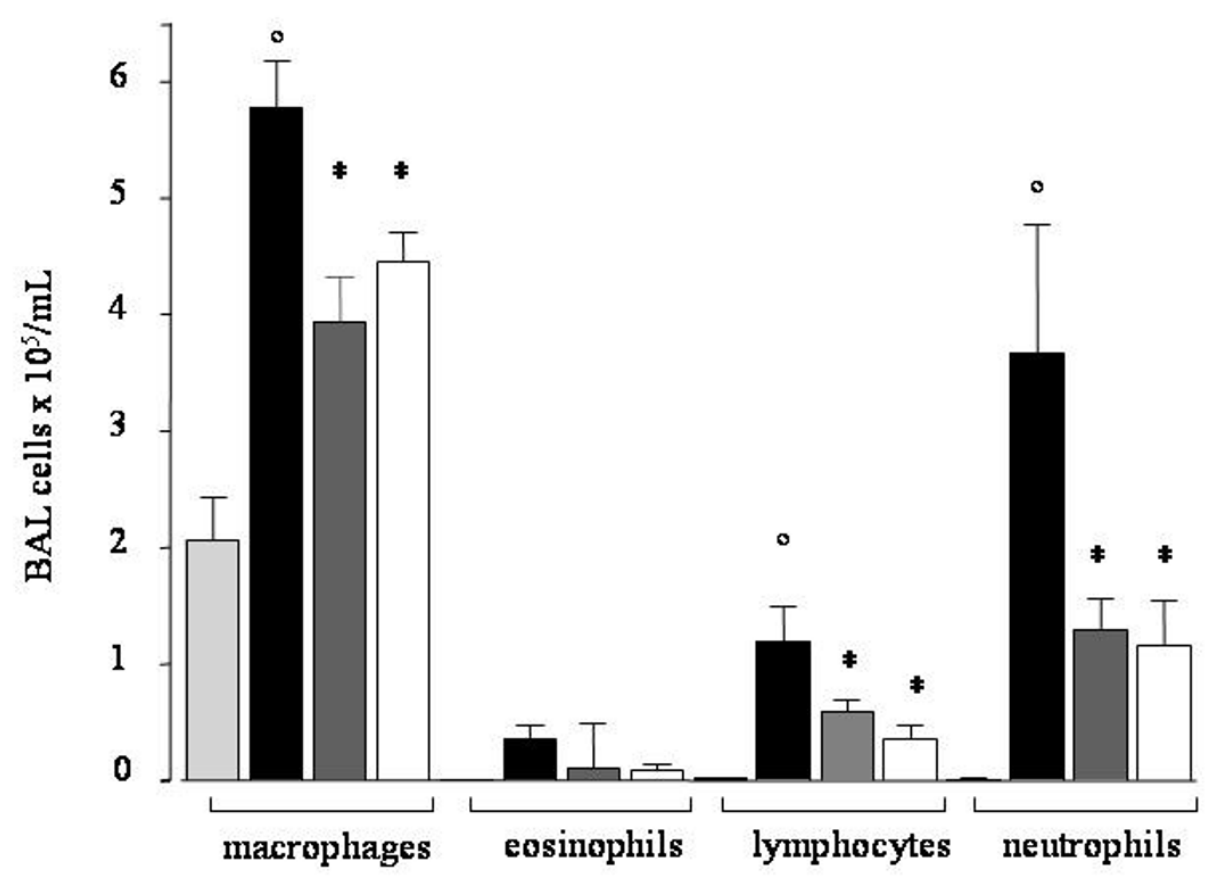

\section{Figure 5}

Effect of pharmacological inhibition of leukotrienes on bleomycin-induced total $(A)$ and differential cellularity (B) ofbronchoalveolar lavage (BAL). Total and differential cells counts for macrophages, lymphocytes, neutrophils and eosinophils per $\mathrm{mL}$ of BAL fluid are shown. Data, expressed as means \pm SEM, are representative of 15 mice for each group. ${ }^{\circ} \mathrm{P}$ $<0.001$ vs. sham, $*_{p}<0.05$ vs. bleomycin. 
tions of treated mice show a reduced degree of fibrosis, but also the alveolar architecture was preserved, indicating that the treatment with leukotrienes antagonists effectively prevented the bleomycin lung damage. In animals treated with MK-571 or Zileuton, lung edema and fall of body weight were virtually absent and inflammatory cells in BAL were significantly reduced. Moreover, we observed a significant reduction of leukocyte infiltration as assessed by the specific granulocyte enzyme MPO. Consistent with proinflammatory cell infiltrate and MPO activity we found that TNF- $\alpha$ was upregulated following intratracheal bleomycin administration. The TNF- $\alpha$ increase was completely abrogated in mice treated with MK-571 and Zileuton.

TNF- $\alpha$ is an "early-wave" cytokine, its role is recognized in a number of fibrotic human pulmonary pathologies[38]. It can induce apoptosis of respiratory epithelium which contributes to the alveolar damage in IPF. Moreover, there is evidence that TNF- $\alpha$ can upregulate the expression of the well known profibrotic cytokine TGF- $\beta 1$ [39]. In fact, TNF- $\alpha$ blockade with either anti-TNF- $\alpha$ antibodies or TNF- $\alpha$ antagonists can inhibit fibrosis[40]. A cys-LT receptor 1 antagonist has been proved able to reduce the NF-kB activation and thus cytokines synthesis in vitro, and in particular TNF- $\alpha$ may be reduced secondarily to this effect[41]. The mechanisms of TNF- $\alpha$ pro-inflammatory activity are likely to involve both direct effects of TNF- $\alpha$ itself on regulation of adhesion molecule expression and induction of other cytokines and growth factors capable of mediating leukocyte chemotaxis and survival. Thus, it is conceivable that leukotrienes blockade results in a reduced inflammatory infiltrate in the lung following bleomycin administration and in an indirect effect on the active TGF- $\beta$ levels in this model.

Similarly to TNF- $\alpha$, we show that interleukin-1 (IL-1) is upregulated following bleomycin administration.

Interleukin- $1 \beta$ is one of the major extracellular proinflammatory cytokines, it is involved fibrotic process and is known to act synergistically with TNF- $\alpha$ [42].

Inhibition of IL-1 $\beta$ prevented the fibrotic reaction induced by bleomycin in mice[43], while its transient expression induces lung injury and pulmonary fibrosis in the late stages of the experimental setting [44].

We show that the IL-1 $\beta$ increase was almost abrogated in mice treated with MK-571 and Zileuton. This class of pharmacological agents has already shown the ability to suppress IL-1 secretion in cultured synovial tissue explants [45], potentially affecting the inflammatory cells infiltrate in tissues and thus the fibrotic response determined by the cascade of cytokines secreted following increased IL-1 $\beta$ release.

Finally, the beneficial effects given by the leukotrienes pharmacological blockade resulted in the abrogation of the mortality at 7 days after bleomycin.

To determine whether LTs play a causal role in fibrotic lung disease, we choose an interventional strategy to target both cysteinyl-LTs as well as $\mathrm{LTB}_{4}$ in the case of Zileuton or only cysteinyl-leukotrienes in the case of MK-571. This approach was selected on the basis of evidence that both classes of LTs are elevated in the bleomycin model as well as in human IPF [46]. Both classes of LTs have important actions that are fully relevant to inflammation as well as fibrogenesis.

Our data shows that both treatments granted a very similar degree of protection from bleomycin, with no evident differences between the two drugs in any of the parameters investigated. This might suggest on a first basis that leukotriene $\mathrm{B}_{4}$ have not a predominant role in mediating inflammation and fibrosis at least in bleomycin treated mice.

It has previously been demonstrated in a mouse model that cys- $\mathrm{LT}_{2}$ receptor is responsible for the fibrotic response to bleomycin administration by using a genetic approach to target this leukotrienes receptor [47]. We found that MK-571, a pharmacological cys- $\mathrm{LT}_{1}$ receptor antagonist, is able to block such response as well. Experimental gene disruption technique might generate a discrete number of variables that makes not feasible a straight parallel with a pharmacological study. On the other hand the receptor specificity of a pharmacological compound such as MK-571 is influenced by several factors related with pharmacological properties of the compound itself. In fact, although MK-571 is a specific cys-LT receptor antagonist, it possesses additional effects on leukotrienes methabolism. Indeed, this compound has been shown to inhibit the ubiquitously expressed multidrug resistance protein 1 (MRP1) as well [48]. MRP1 belongs to the ATP binding cassette transporter superfamily [49], its major physiological role is thought to be ATP-dependent transporter of LT$-\mathrm{C}_{4}$.

MRP1 knock out mice show a reduced inflammatory response induced by arachidonic acid due to impaired LT$\mathrm{C}_{4}$ secretion [50]. Similarly, the specific MRP1 inhibitor MK571 is able to suppress LT $^{-} \mathrm{C}_{4}$ transport in vitro [51].

MRP1 role in immunological responses is not limited to eicosanoids secretion. In example, MRP1 is implicated in $\mathrm{T}$ helper responses. MRP1 is constitutively expressed on Th2 cells while antigen or cytokine stimulation upregu- 
lates its expression on Th1 cells. MK571 has proved to depress $\mathrm{T}$ helper responses by decreasing the release of several cytokines such as IL-4, IFN- $\gamma$ and TNF- $\alpha$ [52].

Considering this, it is tempting to speculate that the protective and anti-inflammatory effect of MK571 we observed could be linked to cys-LT1 receptor blockade as well as impaired cys-LT transport through MRP1. Further research is needed to address the relative role of the dual mechanism of action of MK571 in the bleomycin model of injury. The interest in MK571 action on LT-C 4 transport is relatively recent. Nevertheless, a vast number of studies currently employ this compound as a cys- $\mathrm{LT}_{1}$ receptor antagonist both in vitro and in vivo.

In summary, we have provided the first evidence that antileukotrienes, drugs commonly used for their anti-inflammatory properties to treat asthma and allergic rhinitis, are able in the bleomycin animal model of lung fibrosis to attenuate the acute lung injury and the evolution of fibrotic lung lesions associated with the administration of this anticancer agent.

The beneficial activity of this pharmacological intervention was reflected on some favourable clinical outcomes such as reduced body weight loss, tissue edema and most notably mortality rate. Taken together, our data might further support the rationale for a clinical trial in interstial lung diseases as well as in other fibrotic diseases of the lung interstium including those associated with the usage of known causative drugs using antileukotriene compounds currently available for human use.

\section{Acknowledgements}

We thank Grace Osoata for the help given during manuscript preparation. This work was funded from a Italian Ministry of University and Research Grant (MIUR PRIN 2005, \# 2005069290_003).

\section{References}

I. American Thoracic Society. Idiopathic pulmonary fibrosis: diagnosis and treatment. International consensus statement. American Thoracic Society (ATS), and the European Respiratory Society (ERS). Am J Respir Crit Care Med 2000, 1 61:646-664.

2. Kuhn C: The pathogenesis of pulmonary fibrosis. Monograph Pathol 1993, 36:78-92.

3. Latsi PI, du Bois RM, Nicholson AG, Colby TV, Bisirtzoglou D, Nikolakopoulou A, Veeraraghavan S, Hansell DM, Wells AU: Fibrotic idiopathic interstitial pneumonia: the prognostic value of longitudinal functional trends. Am J Respir Crit Care Med 2003, 1 68:531-537.

4. Selman M, King TE, Pardo A: Idiopathic pulmonary fibrosis: prevailing and evolving hypotheses about its pathogenesis and implications for therapy. Ann Intern Med 200I, I34:I36-I5I.

5. Charbeneau RP, Peters-Golden M: Eicosanoids: mediators and therapeutic targets in fibrotic lung disease. Clin Sci (Lond) 2005, I 08:479-49|.

6. Funk CD: Prostaglandins and leukotrienes: advances in eicosanoids biology. Science 200I, 294: I87I-I875.

7. Ozaki T, Moriguchi H, Nakamura Y, Kamei T, Yasuoka S, Ogura T: Regulatory effect of prostaglandin $\mathrm{E} 2$ on fibronectin release from human alveolar macrophages. Am Rev Respir Dis 1990, | 4 |:965-969.

8. Wardlaw AJ, Hay H, Cromwell O, Collins JV, Kay AB: Leukotrienes, LTC4 and LTB4, in bronchoalveolar lavage in bronchial asthma and other respiratory diseases. J Allergy Clin Immunol 1989, 84:19-26.

9. Wilborn J, Bailie M, Coffey M, Burdick M, Strieter R, Peters-Golden $M$ : Constitutive activation of 5-lipoxygenase in the lungs of patients with idiopathic pulmonary fibrosis. J Clin Invest I996, 97:1827-1836.

10. Peters-Golden M, Bailie M, Marshall T, Wilke C, Phan SH, Toews GB, Moore BB: Protection from pulmonary fibrosis in leukotrienedeficient mice. Am J Respir Crit Care Med 2002, I 65:229-235.

II. Beller TC, Friend DS, Maekawa A, Lam BK, Austen KF, Kanaoka Y: Cysteinyl leukotriene I receptor controls the severity of chronic pulmonary inflammation and fibrosis. Proc Natl Acad Sci U S A 2004, I 01 :3047-3052.

12. Nagase T, Uozumi N, Ishii S, Kita Y, Yamamoto H, Ohga E, Ouchi $Y$, Shimizu T: A pivotal role of cytosolic phospholipase $\mathbf{A}(2)$ in bleomycin-induced pulmonary fibrosis. Nat Med 2002, 8:480-484.

13. Blain JF, Sirois P: Involvement of LTD(4)in allergic pulmonary inflammation in mice: modulation by cysLT(I)antagonist MK-57 I. Prostaglandins Leukot Essent Fatty Acids 2000, 62:36I-368.

14. Mazzon E, Sautebin L, Caputi AP, Cuzzocrea S: 5-lipoxygenase modulates the alteration of paracellular barrier function in mice ileum during experimental colitis. Shock 2006, 25:377-383.

15. Cuzzocrea S, lanaro A, Wayman NS, Mazzon E, Pisano B, Dugo L, Serraino I, Di PR, Chatterjee PK, Di RM, Caputi AP, Thiemermann C: The cyclopentenone prostaglandin I5-deoxy-delta( I 2, I4)PGJ2 attenuates the development of colon injury caused by dinitrobenzene sulphonic acid in the rat. Br J Pharmacol 2003, 138:678-688.

16. Ashcroft T, Simpson JM, Timbrell V: Simple method of estimating severity of pulmonary fibrosis on a numerical scale. J Clin Pathol 1988, 4 I:467-470.

17. Green FH: Overview of pulmonary fibrosis. Chest 2002, I 22:334S-339S.

18. Ozaki T, Hayashi H, Tani K, Ogushi F, Yasuoka S, Ogura T: Neutrophil chemotactic factors in the respiratory tract of patients with chronic airway diseases or idiopathic pulmonary fibrosis. Am Rev Respir Dis 1992, I 45:85-91.

19. Phan SH, McGarry BM, Loeffler KM, Kunkel SL: Binding of leukotriene $\mathrm{C} 4$ to rat lung fibroblasts and stimulation of collagen synthesis in vitro. Biochemistry 1988, 27:2846-2853.

20. Mensing $H$, Czarnetzki BM: Leukotriene B4 induces in vitro fibroblast chemotaxis. J Invest Dermatol 1984, 82:9-I2.

21. Fireman E, Schwartz Y, Mann A, Greif J: Effect of montelukast, a cysteinyl receptor antagonist, on myofibroblasts in interstitial lung disease. J Clin Immunol 2004, 24:4I8-425.

22. Snider GL, Hayes JA, Korthy AL: Chronic interstitial pulmonary fibrosis produced in hamsters by endotracheal bleomycin: pathology and stereology. Am Rev Respir Dis 1978, I | 7:1099-। I08.

23. Slosman DO, Costabella PM, Roth M, Werlen G, Polla BS: Bleomycin primes monocytes-macrophages for superoxide production. Eur Respir J 1990, 3:772-778.

24. Phan SH, Kunkel SL: Inhibition of bleomycin-induced pulmonary fibrosis by nordihydroguaiaretic acid. The role of alveolar macrophage activation and mediator production. $\mathrm{Am} \mathrm{J}$ Pathol 1986, I 24:343-352.

25. Van WJ, Goossens J: Effects of antioxidants on cyclooxygenase and lipoxygenase activities in intact human platelets: comparison with indomethacin and ETYA. Prostaglandins 1983, 26:725-730.

26. Ziboh VA, Yun M, Hyde DM, Giri SN: gamma-Linolenic acid-containing diet attenuates bleomycin-induced lung fibrosis in hamsters. Lipids 1997, 32:759-767.

27. Chilton L, Surette ME, Swan DD, Fonteh AN, Johnson MM, Chilton $\mathrm{FH}$ : Metabolism of gammalinolenic acid in human neutrophils. J Immunol 1996, I 56:294I-2947.

28. Beller TC, Maekawa A, Friend DS, Austen KF, Kanaoka Y: Targeted gene disruption reveals the role of the cysteinyl leukotriene 2 receptor in increased vascular permeability and in bleomy- 
cin-induced pulmonary fibrosis in mice. I Biol Chem 2004, 279:46I29-46I34.

29. Coffey MJ, Phare SM, Peters-Golden M, Huffnagle GB: Regulation of 5-lipoxygenase metabolism in mononuclear phagocytes by CD4 T lymphocytes. Exp Lung Res 1999, 25:617-629.

30. Dupre DJ, Le GC, Gingras D, Rola-Pleszczynski M, Stankova J: Inverse agonist activity of selected ligands of the cysteinylleukotriene receptor I. J Pharmacol Exp Ther 2004, 309:102-108.

31. Piguet PF, Ribaux C, Karpuz V, Grau GE, Kapanci Y: Expression and localization of tumor necrosis factor-alpha and its mRNA in idiopathic pulmonary fibrosis. Am J Pathol 1993, I 43:65I-655.

32. Warshamana GS, Corti M, Brody AR: TNF-alpha, PDGF, and TGF-beta(I) expression by primary mouse bronchiolar-alveolar epithelial and mesenchymal cells: tnf-alpha induces TGF-beta(I). Exp Mol Pathol 200I, 7 I: 13-33.

33. Piguet PF, Vesin C: Treatment by human recombinant soluble TNF receptor of pulmonary fibrosis induced by bleomycin or silica in mice. Eur Respir J 1994, 7:5 I5-5I8.

34. Maeba S, Ichiyama T, Ueno Y, Makata H, Matsubara T, Furukawa S: Effect of montelukast on nuclear factor kappaB activation and proinflammatory molecules. Ann Allergy Asthma Immunol 2005, 94:670-674.

35. Pan LH, Ohtani H, Yamauchi K, Nagura H: Co-expression of TNF alpha and IL-I beta in human acute pulmonary fibrotic diseases: an immunohistochemical analysis. Pathol Int 1996, 46:91-99.

36. Piguet PF, Vesin C, Grau GE, Thompson RC: Interleukin I receptor antagonist (IL-I ra) prevents or cures pulmonary fibrosis elicited in mice by bleomycin or silica. Cytokine 1993, 5:57-6I.

37. Kolb M, Margetts PJ, Anthony DC, Pitossi F, Gauldie J: Transient expression of IL-I beta induces acute lung injury and chronic repair leading to pulmonary fibrosis. J Clin Invest 200I. 107:1529-1536.

38. Rainsford KD, Ying C, Smith F: Effects of 5-lipoxygenase inhibitors on interleukin production by human synovial tissues in organ culture: comparison with interleukin-I-synthesis inhibitors. J Pharm Pharmacol 1996, 48:46-52.

39. Gekeler V, Ise W, Sanders KH, Ulrich WR, Beck J: The leukotriene LTD4 receptor antagonist MK57 I specifically modulates MRP associated multidrug resistance. Biochem Biophys Res Commun 1995, 208:345-352.

40. Cole SP, Bhardwaj G, Gerlach JH, Mackie JE, Grant CE, Almquist KC Stewart AJ, Kurz EU, Duncan AM, Deeley RG: Overexpression of a transporter gene in a multidrug-resistant human lung cancer cell line. Science 1992, 258:1650-1654.

4I. Wijnholds J, Evers R, van Leusden MR, Mol CA, Zaman GJ, Mayer U, Beijnen $J \mathrm{H}$, van $\mathrm{V}$, Krimpenfort $P$, Borst $P$ : Increased sensitivity to anticancer drugs and decreased inflammatory response in mice lacking the multidrug resistance-associated protein. Nat Med 1997, 3:1275-1279.

42. Schaub T, Ishikawa T, Keppler D: ATP-dependent leukotriene export from mastocytoma cells. FEBS Lett 1991, 279:83-86.

43. Prechtl S, Roellinghoff M, Scheper R, Cole SP, Deeley RG, Lohoff M The multidrug resistance protein I: a functionally important activation marker for murine Thl cells. J Immunol 2000, |64:754-76|.
Publish with Bio Med Central and every scientist can read your work free of charge

"BioMed Central will be the most significant development for disseminating the results of biomedical research in our lifetime. "

Sir Paul Nurse, Cancer Research UK

Your research papers will be:

- available free of charge to the entire biomedical community

- peer reviewed and published immediately upon acceptance

- cited in PubMed and archived on PubMed Central

- yours - you keep the copyright

Submit your manuscript here:

http://www.biomedcentral.com/info/publishing_adv.asp
BioMedcentral 